\title{
KONJENITAL AORT KAPAK HASTALIKLARINDA YÜKSEK EFEKTIFF AÇIKLIK ALANLI PROTEZ KAPAK İLE YAPILAN AORT KAPAK REPLASMANI: ERKEN DÖNEM SONUÇLARIMIZ
}

\author{
Aortic Valve Replacement with A Prosthetic Valve with A High Effective Orifice Area in \\ Congenital Aortic Valve Diseases: Our Early Results
}

\author{
Hüseyin GEMALMAZ1 ${ }^{1}$ iD, Yıldırım GÜLTEKİN ${ }^{2}$ iD
}

\author{
${ }^{l}$ Prof. Dr. Cemal Taş̧̧ı̆̆gu Şehir Hastanesi, Kalp ve Damar Cerrahisi Kliniği, İSTANBUL, TÜRKIYE \\ ${ }^{2}$ Kirlkkale Üniversitesi Tip Fakültesi, Kalp ve Damar Cerrahisi A.D., KIRIKKALE, TÜRKIYE

\section{ÖZ}

\section{ABSTRACT}

\begin{abstract}
Amaç: $\mathrm{Bu}$ çalışmada konjenital aort kapak hastalığı olan seçilmiş hastalarda yüksek efektif açıklık alanlı protez kapak kullanılarak yapılan aort kapak replasmanı erken dönem sonuçlarını paylaşmayı amaçladık.
\end{abstract}

Gereç ve Yöntemler: Ağustos 2019-Ağustos 2020 tarihleri arasında toplam 4 pediatrik hastaya mekanik protez kapakla aort kapak replasmanı gerçekleştirildi. Hasta bilgileri retrospektif olarak incelendi. Hastaların tamamı erkekti ve yaşları 10-14 yıl arasındaydı. Üç hastada konjenital aort stenozu vardı ve bir hastada aort stenozu nedeniyle yapilan balon valvuloplasti sonrası orta derece aort yetmezliği olduğu saptandı. Hastaların tamamına median sternotomi ile $16 \mathrm{~mm}$ yüksek efektif açıklık alanlı mekanik protez kapak kullanılarak aort kapak replasmanı yapıldı. Üç hastada aortik anulusun dar olması sebebiyle Manuqian tekniği ile aort kök genişletmesi uygulandı.

Bulgular: Postoperatif dönemde hiçbir hastada ritim problemi olmad. Kanama veya tamponad nedeniyle eksplorasyon gerekmedi. Hastalar 42 (36-48) saat yoğun bakım tedavisi gördükten sonra servise alındı. Hastaneden 6.5 (6-8) günde taburcu oldular. Hiçbir hastada mortalite gelişmedi. Postoperatif erken dönemde, 1. ay ve 6 . aylardaki kontrol ekokardiyografilerinde protez kapakların fonksiyonları normaldi ve patolojik bir gradient saptanmadi. Tromboembolik ve hemorajik bir komplikasyon görülmedi.

Sonuç: Bu çalışmada, konjenital aort kapak hastalığı olan seçilmiş hastalarda yüksek efektif açıklık alanlı protez kapakla yapılan aort kapak replasmanının erken dönem sonuçlarına göre iyi bir alternatif tedavi yöntemi olabileceğini düşünüyoruz. Daha çok hasta üzerinde ve daha uzun dönem takip sonuçlarını içeren çalışmalara gerek vardır.

Anahtar Kelimeler: Konjenital kalp cerrahisi, mekanik protez kapak, aort kapak replasmanı
Objective: In this study, we aimed to share the early results of aortic valve replacement using a prosthetic valve with a high effective orifice area in selected patients with congenital aortic valve disease.

Material and Methods: Between August 2019 and August 2020, a total of 4 pediatric patients underwent aortic valve replacement with a mechanical prosthetic valve. Patient data was analyzed retrospectively. All of the patients were male and their ages were between 10 and 14 years. Three patients had congenital aortic stenosis and one patient had moderate aortic regurgitation after balloon valvuloplasty due to aortic stenosis. After median sternotomy, aortic valve replacement was performed using a $16 \mathrm{~mm}$ highly effective orifice area mechanical prosthetic valve in all patients. In 3 patients, aortic root enlargement was performed by Manuqian technique due to the narrow aortic annulus.

Results: No postoperative rhythm problem was observed in any patient. No surgical exploration was required due to bleeding or tamponade. The patients were taken to the service after receiving intensive care treatment for 42 (36-48) hours. They were discharged from the hospital in 6.5 (6-8) days. Mortality was not observed in any patient. The prosthetic valves were observed to be functioning normally in the postoperative early period, 1st month and 6th month control echocardiographies and no pathological gradient was detected. There were no thromboembolic or hemorrhagic complications.

Conclusion: We think that aortic valve replacement performed with a prosthetic valve with a high effective orifice area in selected patients with congenital aortic valve disease can be a good alternative treatment method according to the early results in this study. There is a need for studies with more patients and longer-term follow-up results.

Keywords: Congenital heart surgery, mechanical prosthetic valve, aortic valve replacement 


\section{GíRIŞ}

Aort kapak fonksiyonları, doğuştan veya sonradan gelişen hastalıklardan dolayı bozulabilir. Anormal aort kapak yapısı, kapakta darlık ve yetersizliklere neden olan fonksiyon bozukluklarına sebep olur. Konjenital sol ventrikül çıkış yolu obstrüksiyonları \%3-8 arasında en sık rastlanılan anomalilerdir (1). Konjenital aort kapak hastalıklarının tedavisinde balon valvüloplasti, cerrahi valvülotomi ve temel cerrahi yöntem olarak aort kapak replasmanı (AVR) operasyonları yapılır. En genel yaklaşımla sol ventrikül çıkış yolu obstrüksiyonu olan olgularda 50 mmHg'nın üzerindeki ortalama gradiyent cerrahi endikasyon oluşturur (2). AVR operasyonları, Ross prosedürü veya mekanik ve biyoprotez kapaklar kullanarak yapılabilir. İlk defa 1967'de Donald Ross bir hastanın kendi pulmoner kapağını aortaya transfer ederek bu tekniği ortaya koydu (3). Ross prosedürünün teknik olarak zor ve zaman alıcı olması, iki kapağa birden müdahale edilmesi, pulmoner kapağın aort pozisyonunda yüksek basınca karşı tepkisinin bilinmemesi ve uzun vade sonuçlarının henüz ortaya konulmamış olması pratikte kullanımını geciktirmiştir. Ancak cerrahlar tarafından seksenli yılların sonunda kullanılmaya başlanmıştır. Çocuk ve genç hastalarda Ross prosedürünün mekanik kapakla yapılan AVR'ye daha üstün yönlerinin olduğu gösteren çalışmalar vardır. Uzmanlaşmış merkezlerde, Ross prosedürünün AVR uygulanacak genç ve orta yaşlı yetişkinler için de düşünülmesi gerektiği belirtilmiştir (4). Yaşam kalitesi Ross ameliyatı olan hasta grubunda daha iyidir ayrıca postoperatif dönemde antikoagülan kullanmayı gerektirmediği için kanama ve stroke riski açısından Ross ameliyatı mekanik AVR ameliyatlarına göre daha avantajlı görünmektedir. Yine mekanik kapak sesinin olmaması hasta konforu açısından bir diğer avantajıdır (5). Bunların yanında Ross ameliyatının önemli bazı dezavantajları da vardır. Yapılan çalışmalarda, kompleks ve öğrenilmesi zor bir cerrahi olan Ross ameliyatında erken mortalite \%2.7 tespit edilirken, AVR operasyonları için erken mortalite \%0.9 tespit edilmiştir
(6). Bunun yanında Ross prosedürünün ameliyat mortalitesini daha düşük bulan yayınlar da bulunmaktadır (7). Ayrıca homogreft veya oto greft sağlanmasının zorluğu ve maliyeti diğer bir dezavantajıdır (8). Antikoagulan kullanımı ve buna bağlı risklerin olmadığı Ross prosedürünün erken mortalite riskinin bazı çalışmalarda yüksek olması, uzun dönemde homogreft veya otogreft dejenerasyonu nedeniyle reoperasyon gerektirebilmesi diğer dezavantajlarını oluşturmaktadır. Çocuk hasta grubunda hızlı büyüme nedeniyle mekanik AVR operasyonlarından bir süre sonra gelişecek uyumsuzluk ve buna bağlı reoperasyon riskleri vardır. Tromboemboli riski nedeniyle antikoagulan kullanma zorunluluğu hastalarda hemorajiye neden olabilir. Her iki yönteminde avantaj ve dezavantajları olması nedeniyle çocuk hasta grubunda eğilim daha çok Ross ameliyatı yönünde olmaktadır (9). Çalışmaların sonuçlarının ise çok farklılık içermesi ise yapılacak tercih konusunda bir belirsizlik oluşturmaktadır. Protez kapağın etkin kapak alanının hastanın vücut yüzey alanına oranla \%85'den küçük olması hasta protez uyumsuzluğu olabileceğini gösterir. $\mathrm{Bu}$ da protezde basınç farkının artışına ve buna bağlı semptomlara yol açar. Hasta protez uyumsuzluğu orta ve uzun vadede yol açacağı hemodinamik sorunlar nedeniyle hastanın yeniden operasyona gitmesine neden olabilir $(10,11)$. Ancak yapılan çalışmalarla geliştirilen yeni nesil ATS “Advanced the standart” kapaklar, yeterli efektif açıklık alanı sağlayarak daha düşük kapak numaraları ile daha yüksek kapak numaralarında sağlanan hemodinamik sonuçlarını elde etmek mümkün olmaktadır. Bu da uzun dönemde daha iyi dayanıklılık ve kalıcılık sağlamaktadır (12).

Biz bu çalışmada konjenital aort kapak hastalığı olan seçilmiş hastalarda yeni nesil yüksek efektif açıklık alanlı mekanik protez kapakla yaptığımız AVR erken cerrahi sonuçlarımızı paylaşmayı amaçladık. 


\section{GEREÇ VE YÖNTEM}

Kliniğimizde Ağustos 2019-Ağustos 2020 tarihleri arasında toplam 4 pediatrik hastaya mekanik protez kapakla AVR işlemi uygulandi. Hastaların verileri hastane bilgi işletim sisteminden ve hasta dosyalarının incelenmesi ile elde edildi. Çalışma 1964 Helsinki Bildirgesi ve daha sonra yapılan değişikliklere veya karşılaştırılabilir etik standartlara uygun olarak yapılmıştır ve kurum izinleri alınmıştır. Hastaların tamamının ameliyat onam formu vardır. Çalışma Memorial Hastanesi Etik Kurulu tarafindan onaylanmıştır (Tarih: 09.06.2020, sayı no: 5).

Hastaların verileri incelenerek; demografik veriler, ameliyat tipleri, kros klemp (KK) süreleri, total by pass süreleri, postoperatif kanama miktarı, kanama sebebiyle yeniden ameliyata alınma, mekanik ventilasyon süreleri, yoğun bakımda ve hastanede kalış süreleri, mortalitelerine bakıldı. Hastaların postoperatif 1. ayda ve 6. ayda yapılan kontrolde, transtorasik iki boyutlu, renkli, spektrum ve sürekli dalga Doppler ekokardiyografi ile değerlendirilen sonuçları incelendi.

Hastaların tamamı erkek ve yaşları 10-14 arasında değişmekteydi. Hastaların hiçbiri medikal tedavi almıyordu. Hastaların transtorasik ekokardiografi incelemesi ile üçünde konjenital aort stenozu tespit edildi. Bir hastaya aort stenozu nedeniyle balon valvüloplasti işlemi uygulanmış, sonrasında gelişen orta aort yetmezliği nedeniyle takibi yapılıyordu. Ekokardiyografi sonucuna göre AVR operasyonu planland1. Ameliyata vücut yüzey alanına göre en az 16 mm yüksek efektif açıklık alanlı mekanik protez kapak takılabilecek hastalar alındı.

Ameliyat öncesi hastaların elektrokardiyografileri çekildi ve invaziv arter monitorizasyonu, santral venöz basınç monitorizasyonu ve pulse oksimetre monitorizasyonları yapıld1. Foley idrar sondası ve nazal 1S1 probu takıldı. Anestezi için operasyondan 30 dakika önce premedikasyon amaci ile morfin $0.05 \mathrm{mg} / \mathrm{kg}$ intramusküler olarak yapıldı. İndüksiyonda etomidat 0.3 $\mathrm{mg} / \mathrm{kg}$ intravenöz yolla verildi. Sonra nöromüsküler bloker rokuronyum $0.9 \mathrm{mg} / \mathrm{kg}$ verildi. Hastalara \%2-4 MAC değerinde sevofluran anestezik başlandı.

Hastalara genel anestezi altında rutin olarak median sternotomi yapıldı. Heparin yapıldıktan sonra yeterli aktive koagülasyon zamanına (ACT) ulaşılınca (ACT $\geq 400 \mathrm{sn}$ ) kanülasyon işlemine geçildi. Aortadan arterial kanül ve two stage tek venöz kanülasyon ile kanüle edilerek ekstrakorporeal dolaşıma geçildi. Orta derece hipotermi sağland. Rutin olarak standart izotermik kan kardiyoplejisi kullanılarak kardiyak arrest sağlandı. 3 hastanın aortik anulusunun dar olması sebebiyle Manuquian tekniği ile perikardial yama kullanılarak aort kök genişletme işlemi uygulandı. Bir hastanın anulus çapı uygun olduğu için genişletme yapılmadi. Hastaların tamamında ATS $16 \mathrm{~mm}$ Medtronic Open Pivot AP360 ${ }^{\circledR}$ bileaflet mekanik protez kapak kullanılarak tek tek sütür tekniği ile AVR işlemi yapıldı. Kalp spontan sinüs ritminde çalıştı. Pace maker ihtiyacı olmadı. Hastaların tamamı entübe olarak dopamin desteğiyle yoğun bakıma alındı. Ventilatöre bağlandılar ve monitörize edildiler.

Verilerin istatistiksel analizi için SPSS for Windows 21.0 paket programı (SPSS Inc., Chicago, IL, ABD) kullanıldı. Normal dağılıma sahip sayısal verilerde merkezi eğilim ölçüleri olarak aritmetik ortalama olarak gösterilmiştir. Normal dağılım göstermeyen sayısal verilerde medyan, minimum ve maksimum değerler kullanılmıştır. Kategorik değişkenler yüzde olarak gösterilmiştir.

\section{BULGULAR}

Çalışmaya dahil edilen dört hastanın demografik verileri ve tanıları Tablo 1'de verilmiştir. Hastaların ortalama (vaka sayısı az olduğu için ortalama değer yerine ortanca değerinin verilmesi daha uygun olabilir) ejeksiyon fraksiyonu $52.25 \mathrm{mmHg}$ ve ortalama gradiyent 61.25 $\mathrm{mmHg}$ olarak hesaplandi. Hastaların ekokardiyografi bulguları Tablo 2' de gösterilmiştir. 
Bir hastaya AVR, üç hastaya AVR ve Manuquian yöntemiyle aort kök genişletme ameliyatı yapıldı. Kros klemp süresi 107 (79-174) dakika ve total bypass süresi
158 (104-223) dakika olarak tespit edildi. Hiçbir hastada ritim bozukluğu gelişmedi. Operatif veriler Tablo 3 'te gösterilmiştir.

Tablo 1: Hasta verileri

\begin{tabular}{cccccc}
\hline Yaş (yıl) & Cinsiyet & Ağırlık $(\mathrm{kg})$ & Boy $(\mathrm{m})$ & VYA $\left(\mathrm{kg} / \mathrm{m}^{2}\right)$ & Tanı \\
\hline 11 & E & 22.6 & 1.16 & 0.84 & AS + orta AY \\
10 & E & 24.4 & 1.34 & 0.97 & AS \\
14 & E & 36.5 & 1.35 & 1.16 & AS \\
10 & E & 43 & 1.34 & 1.24 & AS
\end{tabular}

AS: Aort stenozu, VYA: Vücut yüzey alanı, AY: Aort yetmezliği

Tablo 2: Ekokardiyografi verileri

\begin{tabular}{lcccccc}
\hline Hasta & IVSd (mm) & LVDd (mm) & LVSd (mm) & LVPWd (mm) & EF (\%) & Ortalama gradiyent (mmHg) \\
\hline 1 & 8.5 & 49 & 27 & 8.5 & 44 & 49 \\
2 & 8 & 51 & 26 & 8 & 55 & 60 \\
3 & 8.4 & 50 & 24 & 8.2 & 56 & 72 \\
4 & 7.7 & 53 & 27 & 8.3 & 54 & 65
\end{tabular}

IVSd: İntraventriküler septal kalınlık, LVDd: Sol ventrikül diastolik çap, LVSd: Sol ventrikül sistolik çap, LVPWd: Sol Ventrikül Posterior duvar kalınlı̆̆ 1 EF: Ejeksiyon fraksiyonu

Tablo 3: Operatif veriler

\begin{tabular}{llcccc}
\hline Hastalar & $\begin{array}{l}\text { Yapılan } \\
\text { Ameliyat }\end{array}$ & $\begin{array}{c}\text { KK Süresi } \\
(\mathrm{dk})\end{array}$ & $\begin{array}{c}\text { Total Bypass } \\
\text { Süresi }(\mathrm{dk})\end{array}$ & $\begin{array}{c}\text { Postoperatif } \\
\text { Ritm }\end{array}$ & $\begin{array}{c}\text { İnotrop Desteği } \\
\text { Dopamin }(\mathrm{mcg} / \mathrm{kg} / \mathrm{dk})\end{array}$ \\
\hline 1 & AVR & 80 & 104 & Sinüs & 5 \\
2 & AVR+Manuquian & 174 & 223 & Sinüs & 7 \\
3 & AVR+Manuquian & 79 & 139 & Sinüs & 5 \\
4 & AVR+Manuquian & 134 & 177 & Sinüs & 8 \\
\hline
\end{tabular}

KK: Kross klemp, AVR: Aort valv replasmanı

Hastaların ekstübasyon süresi 4.35 (3.3-5.4) saatti ve 145 (100-200) mm/gün drenajı oldu. Hastalar 42 (36-48 saat yoğun bakım kalış süresi sonrasında servise alındılar. Postoperatif hastanede yatış süresi 6.5 (6-8) gündü. Postoperatif 1. ay ve 6. ay kontrol transtorasik ekokardiyografide gradiyent sirasiyla 22.5 (19-23)
$\mathrm{mmHg}, 18.5$ (16-20) mmHg olarak tespit edildi. Protez kapak fonksiyonları normaldi. Hiçbir hastada enfeksiyon, solunum problemi, tromboemboli ve hemoraji görülmedi. Postoperatif veriler Tablo 4'te gösterilmiştir. 
Tablo 4: Postoperatif veriler

\begin{tabular}{|c|c|c|c|c|c|c|}
\hline \multirow{2}{*}{ Hasta } & \multirow{2}{*}{$\begin{array}{l}\text { Ekstübasyon } \\
\text { Süresi (saat) }\end{array}$} & \multirow{2}{*}{$\begin{array}{l}\text { Drenaj } \\
\text { (ml/gün) }\end{array}$} & \multirow{2}{*}{$\begin{array}{c}\text { YB Yatış } \\
\text { Süresi (saat) }\end{array}$} & \multirow{2}{*}{$\begin{array}{l}\text { Hastane Yatış } \\
\text { Süresi (gün) }\end{array}$} & \multicolumn{2}{|c|}{ Postoperatif Ortalama Gradiyent $(\mathrm{mmHg})$} \\
\hline & & & & & 1. ay & 6. ay \\
\hline 1 & 4.2 & 100 & 36 & 6 & 19 & 16 \\
\hline 2 & 5.4 & 150 & 44 & 8 & 22 & 19 \\
\hline 3 & 3.3 & 140 & 40 & 7 & 23 & 20 \\
\hline 4 & 4.5 & 200 & 48 & 6 & 21 & 18 \\
\hline
\end{tabular}

YB: Yoğun bakım

\section{TARTIŞMA}

Çocuk hasta grubunda aort kapak cerrahisi konusunda tedavi yöntemi olarak tam anlamıyla bir görüş birliği yoktur. Araştırma sonuçlarının farklılı̆̆ı, çalışmalarının genellikle tek merkezli olması, çok merkezli çalışmaların az olması ve her tedavi yönteminin kendine göre avantaj ve dezavantajları barındırması konu üzerinde tam bir görüş birliği oluşmasına engel olmaktadır.

Genel eğilim önceliğin Ross prosedürü yönünde olması şeklindedir. 20 yıllık Ross prosedürü sonuçlarının takip edildiği çalışmada, genel populasyonla kıyaslandığında Ross prosedürü uygulanan çocukların yaşıtlarına yakın bir gelişim izlediği görülmüştür (13). Düşük endokardit riski, uzun dönem hemodinamik sonuçlarının iyi olması, antikoagülan kullanmak zorunluluğunun olmamas1, büyüme ile oluşabilecek değişikliklere uyum sağlaması önemli avantajlarıdır (14,15). Genellikle, warfarin kullanımının istenmediği, küçük bebeklerde veya ileride gebelik düşünen genç kızlarda önemli bir tercih nedenidir (16). Bunun yanında kompleks bir cerrahi olması, postoperatif kanamaların olması, bir kapak hastalığının iki kapak hastalığına dönüştürülmesi, pulmoner kapağın alınması sonucunda sağ ventrikül çıkış yolunun yeniden düzenlenmesi, uzun dönemde pulmoner otogrefte bağlı anulus dilatasyonu ve buna bağlı aortik yetmezlik, pulmoner homogrefte bağlı dejenerasyon sorunları gibi birçok riski içinde barındırmaktadır. Standart AVR sonrası reoperasyon ameliyatlardan farklı olarak, Ross prosedüründen sonra reoperasyon daha karmaşıktır ve özellikle her iki kapakta yeniden müdahale gerektiren durumlarda daha yüksek bir ameliyat riski ile karşı kaşıya kalınır (17). Bu yüzden, prosedürün düşük mortalite ve morbidite ile yapılabilmesine, endikasyonlarının gittikçe genişletilmesine karşın, tekniğin öğrenim sürecinin zor ve deneyim gerektirmesi, dolayısıyla hastaların seçiminde prosedürden sağlayacağı fayda ile alınacak riskin çok iyi hesaplanması gerektiği açıktır (18).

Mekanik kapaklar ile yapılan AVR operasyonları Ross prosedürüne göre daha basit ve standart bir ameliyat tekniği olması ve uzun dönem dayanıklılığının çok iyi olması en önemli avantajlarını oluşturmaktadır. Bunun yanında beklenen uzun yaşam süresinde kullanılacak antikoagülan ve buna bağlı kanama veya tromboemboli komplikasyonu riskleri, çocuğun büyümesi sonucunda ortaya çıkabilecek kapak uyumsuzluğu ve buna bağlı sol ventrikül fonksiyon bozuklukları dezavantajlarıdır $(19,20)$. Bununla birlikte kalp ve aort boyutları doğumda erişkin düzeyinin \%50'sini oluştururken, 5 yaşında \%75'ine ve 12 yaşında \%90'ına erişebilmekte ve konjenital aort darlıklarında yapısal ve gelişimsel nedenlere bağlı olarak bu oranlar değişkenlik gösterebilmektedir. Bundan dolayı bu yaş gruplarında konjenital aort kapak replasmanında uyumsuzluk probleminin daha az olacağı öngörülmektedir (21).

Biz ameliyatlarda AVR amaciyla medronic open pivot AP 360 ATS kapağını kullandık. Bu ATS kapaklar 
yüksek efektif açıklık alanı olan, güçlü karbon materyalden yapılmış uzun dayanıklılığı olan, yüksek güvenlikli profilde, trombojenik ve hemolitik etkileri düşük olan kapaklardır (22). ATS kapaklar uzun yıllardır kullanımda olup uzun dönem sonuçları yayınlanmıştır (23). Mekanik kapak sonrasında kullanılacak antikoagülan ve buna bağlı kanama önemli bir sorun olarak durmaktadır. "International Normalized Ratio” (INR) değeri yükseldikçe kanama riskinin artması, düşük INR değerleri ile en optimal antitrombotik etkinin elde edilmesi fikrine yönlendirmiştir. ATS kapak konfigurasyonu ve kanın y1kama etkisi nedeniyle INR değerlerinin 1,6 ile 2 arasında tutmanın yeterli antitrombotik etkiyi sağladığı gösterilmiştir (24). Bu da bizi yüksek INR değerlerinden kaçınmamıza ve postoperatif INR değerini 2 civarında tutmaya imkan vermiştir. Bu daha düşük INR düzeyi ile elde edilecek antikoagulasyonla, özellikle uzun dönem takipte, bir dezavantaj gibi görünen kanama riskinin de minumumda tutulabileceğini düşünüyoruz.

Mekanik protez kapaklarda warfarin kullanma zorunluluğu ileride kadın hastalarda gebelik durumunda warfarinin teratojenik olması nedeniyle anne ve fetüs için bir sorun oluşturabilmektedir. Olası bir gebelik durumunda ilk 3 trimesterda warfarin yerine heparin veya düşük molekül ağırlıklı heparin kullanmak gerekebilir. Bu da anne açısından kapakta tromboemboli riski oluşturabilir (25). Prostetik kalp kapağı olan hastaların, özellikle doğuştan lezyonlar nedeniyle aort kapak protezi takılmış olan hastaların, kardiyak mortalite, antikoagülasyonla ilişkili mortalite ve tromboembolik riskler artmış olmasına rağmen, mitral protez kapaklara göre gebeliği çok daha iyi tolere ettiklerine dair çalışmalar vardır (26). Biz bu nedenden dolayı özelikle erkek hastalarda yüksek efektif açıklık alanlı mekanik protez kapağı kullanmayı tercih ettik. Hastalarımızın tamamı erkekti.

Mekanik AVR'lerdeki ikinci önemli sorun ise büyümeye bağlı olarak gelişecek kapak uyumsuzluk problemleridir. ATS open pivot AP 360 kapaklarla yapılan çalışmalar düşük numaralarda diğer kapaklara oranla daha iyi hemodinamik etkiye ulaşıldığını göstermiştir (27). Pirolitik karbon, ince ve güçlü orifis yapısı geniş geometrik açıklık alanı sağlar (28). Ekokardiyografi ile yapılan çalışmalarda standart kapak numaralarıyla karşılaştırıldığında 3 numara daha avantaj sağladığı, 16 numara bir kapağın, standart 19 numara kapağa eşit hemodinamik etki sağladığı gösterilmiştir (29). Ayrıca tek plan orifis yapısı kapağın oturmasını kolaylaştırır (30). Biz bu ameliyatlarda büyümeye bağlı uyumsuzluk problemlerinden kaçınmak için en yüksek kapak numarasını kullanmayı tercih ettik. Ayrıca Open Pivot kapaklar diğer mekanik protez kapaklara göre belirgin şekilde sessiz çalışmaları hasta için bir konfor yaratmaktadir (31).

Ross prosedürü ile AVR yapılan bir çalışmada total bypass süresi 173 ile 382 dakika arasında (ortalama 242.5 dk.), KK süresi ise 108 ile 227 dakika arasında (ortalama $147.2 \mathrm{dk}$.) değiştiği gösterilmiş (32). Perioperatif olarak ortalama total bypass süremiz 158 (104-223) dakika, ortalama KK süresi 107 (79-174) dakika oldu. Ross ameliyatına göre daha kısa pompa ve KK süresi pompanın sistemik yan etkilerinden korunmak yönünden postoperatif dönemde önemlidir.

Ross prosedürünün en önemli operatif problemlerinden biri hemostazda yaşanan güçlüklerdir. Anastomoz hatlarının fazlalığı yanında, pulmoner otogreftin eksizyonundan sonra sağ ventrikül diseksiyon alanlarının bir kısmının kalbin dışında kalıyor olması bu yüzeydeki kontrolü zor kanamalar önemli bir problem oluşturabilir (33). Çalışmada drenaj miktarları ortalama 145 (100-200) cc bulundu. Kanama ve tamponad nedeniyle eksplorasyona alınan hasta olmadı. Güvenlik amacıyla 2. gün direnlerini çekildi. Yoğun bakım süreleri ortalama 42 (36-48) saattir. Hastane kalış süreleri ortalama 6.5 (6-8) gün olup INR değerleri 2 ye çıkınca hastalar taburcu edildi. Postoperatif enfeksiyon, ritim bozuklukları ve solunumsal komplikasyonlar yaşanmadı. Hastalarımızda hastanede yatarken ve 6 aylık takiplerinde mortalite görülmedi. Aort darlığında 
(AD) ekokardiyografide doppler gradiyenti hafif $\mathrm{AD}$ $\leq 25 \mathrm{mmHg}$, orta $\mathrm{AD} \leq 25-40 \mathrm{mmHg}$, önemli $\mathrm{AD} \geq 40$ mmHg olarak kabul edilir (34). Postoperatif taburculuk sonras1 1. ve 6. ayda yapılan kontrol ekokardiyografide patolojik bir gradiyent tespit edilmedi ve mekanik protez kapak fonksiyonları normal tespit edildi.

Konjenital aort kapak hastalıklarında tedavi alternatifleri çeşitli olsa da bu tedavilerin avantaj ve dezavantajları nedeniyle seçim yapmak zor olabilmektedir. Ross prosedürü uzun dönem sonuçları açısından daha ön planda görünse de de özellikle 16 numara kapak takılabilecek anulus ve aort boyuna ulaşmış vücut yüzey alanı olan erkek çocuklarda yüksek efektif açıklık alanı olan ATS mekanik kapaklarla yapılan AVR ameliyatlarının bir alternatif olarak akılda tutulması gerektiğini düşünüyoruz. Erişkin dönemde ulaşacakları vücut kitle indekslerini bilmediğimiz çocukların daha basit bir ameliyat tekniğiyle mevcut patolojiyi düzeltmek, yalnız tek kapak hastalığının takibini yapmak ve reoperasyon gerekirse de Ross prosedürü reoperasyonuna göre daha basit bir şekilde uygulanabilecek mekanik AVR reoperasyonun hasta için bir avantaj sağlayacağını düşünüyoruz. Hasta sayısının az olması ve uzun dönem sonuçlarının henüz belli olmaması bu çalışmanın kısıtlayıcı taraflarını oluşturmaktadır.

Çatışma Beyanı: Yazarların beyan edeceği herhangi bir çıkar çatışması yoktur.

Araştırmacıların Katkı Oranı Beyanı: Yazarlar makaleye eşit oranda katkı sağlamış olduklarını beyan ederler. Anafikir-planlama: HG, YG; analiz-yorum: HG, YG; veri sağlama: HG, YG; yazım; HG, YG; gözden geçirme ve düzeltme: HG, YG; onaylama: HG, YG.

Destek ve Teşekkür Beyanı: Çalışma için hiçbir kurum ya da kişiden finansal destek alınmamıştır.

Etik Kurul Onamı: Memorial Hastanesi Etik Kurulu; tarih: 09.06.2020, sayı no: 5 .

\section{KAYNAKLAR}

1. Park MK. Pediatric Cardiology for Practitioners. 5th ed. Philadelphia. Mosby Company, 2008.

2. Suarez de Lezo J, Pan M, Medina A, Romero M, Melian F, Segura $\mathrm{J}$ et al. Immediate and follow-up results of transluminal balloon dilation for discrete subaortic stenosis. J AM Coll Cardiol. 1991;18(5):1309-15.

3. Ross DN. Replacement of aortic and mitral valves with a pulmonary autograft. Lancet. 1967;2(7523):956-8.

4. Mazine A, David TE, Rao V, Hickey EJ, Christie S, Manlhiot C et al. Long-term outcomes of the Ross procedure versus mechanical aortic valve replacement: propensity-matched cohort study. Circulation. 2016;134(8):576-85.

5. Sievers HH, Stierle U, Charitos EI, Takkenberg JJM, Hörer J, Lange R et al. A multicenter evaluation of the autograft procedure for young patients undergoing aortic valve replacement: update on the German Ross Registry. Eur J Cardiothorac Surg. 2016;49(1):212-8.

6. Alsoufi B, Al-Halees Z, Manlhiot C, McCrindle BW, Al-Ahmadi M, Sallehuddin A et al. Mechanical valves versus the Ross procedure for aortic valve replacement in children: propensity-adjusted comparison of long-term outcomes. J Thorac Cardiovasc Surg. 2009:137(2);362-70.

7. Sharabiani MTA, Dorobantu DM, Mhani AS, Turner M, Tometzki AJP, Angelini GD et al. Aortic valve replacement and the Ross operation in children and young adults. J Am Coll Cardiol. 2016;67(24):285870 .

8. Weymann A, Sabashnikov A, Popov AF. The Ross procedure: suitable for everyone? Expert Rev. Cardiovasc. Ther. 2014;12(5):549-6.

9. Etnel JR, Elmont LC, Ertekin E, Mokhles MM, Heuvelman HJ, Roos-Hesselink JW et al. Outcome after aortic valve replacement in children: A 
systematic review and meta-analysis. J Thorac Cardiovasc Surg. 2016;151(1):143-52.

10. Dale J, Myhre E. Intravascular hemolysis in the late cause of aortic valve replacement. Relation to valve type, size and function. Am Heart J. 1978;96(1):2430 .

11. İlhan G, Bozok Ş, Çayır MÇ, Tüfekçi N, Küçüker ŞA. Comparison of early treatment outcomes after aortic valve replacement with sutureless, bioprosthetic, and mechanical valves: Our singlecenter experience with 140 patients. Cardiovasc Surg Int. 2020;7(1):20-9.

12. Westaby S, Van Nooten G, Sharif H, Pillai R, Caes F. Valve replacement with the ATS open pivot bileaflet prosthesis. Eur J Cardiothorac Surg. 1996;10(8):660-5.

13. David TE, David C, Woo A. Manlhiot C. The Ross procedure: outcomes at 20 years. $\mathrm{J}$ Thorac Cardiovasc Surg. 2014;147(1):85-93.

14. Elkins RC, Thompson DM, Lane MM, Elkins CC, Peyton MD. Ross operation: 16-year experience. J Thorac Cardiovasc Surg. 2008;136(3):623-30.

15. Takkenberg JJ, Kappetein AP, van Herwerden LA, Witsenburg M, Van Osch-Gevers L, Bogers AJ. Pediatric autograft aortic root replacement: a prospective follow-up study. Ann Thorac Surg. 2005;80(5):1628-33.

16. Mazine A, El-Hamamsy I, Ouzounian M. The Ross procedure in adults: which patients, which disease? Curr Opin Cardiol. 2017;32(6):663-71.

17. Mokhles MM, Rizopoulos D, Andrinopoulou ER, Bekkers JA, Roos-Hesselink JW, Lesaffre E et al. Autograft and pulmonary allograft performance in the second post-operative decade after the Ross procedure: insights from the Rotterdam Prospective Cohort Study. Eur Heart J. 2012;33(17):2213-24.

18. Elkins RC, Knott- Craig CJ, Ward KE, Lane MM: The Ross operation in children: 10-year experience. Ann Thorac Surg. 1998;65(2):496-502.
19. Brown JW, Ruzmetov M, Vijay P, Rodefeld MD, Turrentine MW. Surgery for aortic stenosis in children: a 40-year experience. Ann Thorac Surg. 2003;76(5):1398-411.

20. Elkins RC, Lane MM, McCue C. Ross operation in children: late results. J Heart Valve Dis. 2001;10(6):736-41.

21. Fullerton DA. Aortic valve replasman. In: Kaiser LR, Kron IL, Spray TL, eds. Mastery of Cardiothoracic Surgery. 2nd ed. Philadelphia. Lippincott Williams\&Wilkins, 2007:410-23.

22. Emery RW, Van Nooten GJ, Tesar PJ. For the Investigators for the ATS Clinical Open Pivot Heart Valve Food and Drug Administration Study the initial experience with the ATS medical mechanical cardiac valve prosthesis. Ann Thorac Surg. 2003;75(2):444-52.

23. Sezai A, Hata M, Niino T, Yoshitake I, Kasamaki Y, Hirayama A et al. Fifteen years of experience with ATS mechanical heart valve prostheses. J Thorac Cardiovasc Surg. 2010;139(6):1494-1500.

24. Van Nooten GJ, Caes F, Francois K, Bove T, Vandenplas G, De Pauw M et al. Fifteen years single-center experience with the ATS bileaflet valve. J Heart Valve Dis. 2009;18(4):444-52.

25. Akhtar RP, Abid AR, Zafar H, Cheema MA, Khan JS. Anticoagulation in pregnancy with mechanical heart valves: 10-year experience. Asian Cardiovasc Thorac Ann. 2007;15(6):497-501.

26. Sillesen M, Hjortdal V, Vejlstrup N, Sørensen K. Pregnancy with prosthetic heart valves - 30 years' nationwide experience in Denmark. Eur $\mathbf{J}$ Cardiothorac Surg. 2011;40(2):448-54.

27. Shiono M, Sezai Y, Sezai A, Omoto R, Kyo S, Hatanaka $\mathrm{M}$ et al. Multi-institutional experience of the ATS Open Pivot bileaflet valve in Japan. Ann Thorac Cardiovasc Surg. 1996;2(1):51-8.

28. Krian A. Clinical results of a large series of ATS valve implants. In: Krian A, Matloff JM, Nicoloff KÜTFD | 204 
DM, eds. Advancing the Technology of Bileaflet Mechanical Heart Valves: 1st ed. Darmstad. Springer Verlag GmbH \& Co. KG, 1998:53-71.

29. Jazayeri S, Gomez MC, Tatou E, Ecarnot A, Saleh $\mathrm{M}$, Bouchot $\mathrm{O}$ et al. Clinical experience and Doppler echocardiographic assessment of the first one hundred ATS AP (advanced performance) prosthetic valve in the aortic position. J Heart Valve Dis. 2003;12(5):628-34.

30. Emery RW, Krogh CC, Jones DJ, Nicoloff DM, Blake DP, Arom KV. Five-year follow up of the ATS mechanical heart valve. J Heart Valve Dis. 2004;13(2):231-8

31. Sezai A, Shiono M, Orime Y, Hata H, Yagi S, Negishi $\mathrm{N}$ et al. Evaluation of valve sound and its effects on ATS prosthetic valves in patient's quality of life. Ann Thorac Surg. 2000;69(2):507-12.

32. Sarıglu T, Erek E, Kinoglu B, Salihoglu E, Şaşmazel A, Sarıoglu A, et al. Aort kapak hastalığında pulmoner otogreft (ross operasyonu) ve perikardiyal yaka tekniği. Türk Kardiyol Dern Arş. 2001;29(3):465-70.

33. Oury JH. Clinical aspects of the Ross procedure: Indications and contraindications. Sernin Thorac Cardiovasc Surg. 1996;8(4):328-35.

34. Schenider DJ, Moore JW. Aortic Stenosis. In: Allen HD, Driscoll DJ, Shaddy RE, Feltes TF, eds. Moss\&Adams' Heart Disease in Infants, Children and Adolescents, Including the Fetus and Young Adult. 8th ed. Philadelphia. Lippincott WilliamsWilkins, 2013:1023-43. 